\title{
Diabetes and hypertension markedly increased the risk of ischemic stroke associated with high serum resistin concentration in a general Japanese population: the Hisayama Study Haruhiko Osawa $^{\dagger 1}$, Yasufumi Doi ${ }^{\dagger 2,3}$, Hideichi Makino*1, Toshiharu Ninomiya ${ }^{3}$, Koji Yonemoto ${ }^{3}$, Ryoichi Kawamura ${ }^{1,3}$, Jun Hata ${ }^{3}$, Yumihiro Tanizaki ${ }^{3}$, Mitsuo Iida ${ }^{2}$ and Yutaka Kiyohara*3
} \begin{abstract}
Medicine, Graduate School of Medical Sciences, Kyushu University, Fukuoka, Japan
Email: Haruhiko Osawa - harosawa@m.ehime-u.ac.jp; Yasufumi Doi - doi@intmed2.med.kyushu-u.ac.jp; Hideichi Makino* - hidemak@m.ehime-u.ac.jp; Toshiharu Ninomiya - nino@intmed2.med.kyushu-u.ac.jp; Koji Yonemoto - yonemoto@envmed.med.kyushu-u.ac.jp; Ryoichi Kawamura - ryokawa@m.ehime-u.ac.jp; Jun Hata - junhata@envmed.med.kyushu-u.ac.jp; Yumihiro Tanizaki - yumi@envmed.med.kyushu-u.ac.jp; Mitsuo Iida - iidam@intmed2.med.kyushu-u.ac.jp; Yutaka Kiyohara* - kiyohara@envmed.med.kyushu-u.ac.jp

* Corresponding authors †Equal contributors
\end{abstract}

Address: ${ }^{1}$ Department of Molecular and Genetic Medicine, Ehime University Graduate School of Medicine, Ehime, Japan, ${ }^{2}$ Department of Medicine and Clinical Science, Graduate School of Medical Sciences, Kyushu University, Fukuoka, Japan and ${ }^{3}$ Department of Environmental

Published: 18 November 2009

Cardiovascular Diabetology 2009, 8:60 doi:10.1 186/1475-2840-8-60
Received: 29 July 2009

Accepted: 18 November 2009

This article is available from: http://www.cardiab.com/content/8/I/60

(c) 2009 Osawa et al; licensee BioMed Central Ltd.

This is an Open Access article distributed under the terms of the Creative Commons Attribution License (http://creativecommons.org/licenses/by/2.0), which permits unrestricted use, distribution, and reproduction in any medium, provided the original work is properly cited.

\begin{abstract}
Background: Resistin, secreted from adipocytes, causes insulin resistance in mice. The relationship between resistin and coronary artery disease is highly controversial, and the information regarding resistin and ischemic stroke is limited. In the present study, the association between serum resistin concentration and cardiovascular disease (CVD) was investigated in a general Japanese population.
\end{abstract}

Methods: A total of 3,20I community-dwelling individuals aged 40 years or older (I,382 men and I,8I9 women) were divided into quintiles of serum resistin, and the association between resistin and CVD was examined cross-sectionally. The combined effect of either diabetes or hypertension and high serum resistin was also assessed. Serum resistin was measured using ELISA.

Results: Compared to those without CVD, age- and sex-adjusted mean serum resistin concentrations were greater in subjects with CVD $(p=0.002)$ or ischemic stroke $(p<0.001)$, especially in those with lacunar and atherothrombotic infarction, but not elevated in subjects with hemorrhagic stroke or coronary heart disease. When analyzed by quintile of serum resistin concentration, the age- and sex-adjusted odds ratio (OR) for having CVD and ischemic stroke increased with quintile of serum resistin ( $p$ for trends, 0.02 for $C V D,<0.001$ for ischemic stroke), while such associations were not observed for hemorrhagic stroke or coronary heart disease. Compared to the first quintile, the age- and sex-adjusted OR of ischemic stroke was greater in the third $(O R=3.54 ; 95 \%$ confidence interval $[\mathrm{Cl}]$, I.I7-I0.67; $\mathrm{p}=0.02)$, fourth $(\mathrm{OR}=4.48 ; 95 \% \mathrm{Cl}, 1.53-13.09 ; \mathrm{p}=0.006)$, and fifth quintiles $(O R=4.70 ; 95 \% \mathrm{Cl}, 1.62-13.61 ; \mathrm{p}=0.004)$. These associations remained substantially unchanged even after adjustment for other confounding factors including high-sensitivity C-reactive protein. In the stratified analysis, the combination of high serum resistin and either diabetes or hypertension markedly increased the risk of ischemic stroke.

Conclusion: Elevated serum resistin concentration appears to be an independent risk factor for ischemic stroke, especially lacunar and atherothrombotic infarction in the general Japanese population. The combination of high resistin and the presence of either diabetes or hypertension increased the risk of ischemic stroke. 


\section{Background}

Resistin belongs to a family of cysteine-rich secretory proteins called resistin-like molecules [1]. In rodents, resistin is derived almost exclusively from adipose tissue, and serum resistin is elevated in animal models of obesity and insulin resistance [2-4]. On the other hand, in humans, monocytes and macrophages express resistin at high levels [5]; thus, the pathophysiological role of resistin may differ between species. In vitro, resistin activates human endothelial cells, leading to increased expression of adhesion molecules, and induces human aortic muscle cell proliferation $[6,7]$. Furthermore, several clinical and epidemiological studies have revealed positive associations between plasma concentrations of resistin and proinflammatory cytokines [8-10], which are emerging risk factors for cardiovascular disease (CVD). These findings suggest that resistin contributes to the development of atherosclerosis and thereby is linked to clinical vascular events. However, the relationship between resistin and coronary artery disease is highly controversial [11-14]. Furthermore, the information regarding resistin and ischemic stroke in general population is limited to only one epidemiological study that reported no association between circulating resistin and ischemic stroke [14].

The aim of the present study was to examine the association between serum resistin and CVD in a cross-sectional study of a defined Japanese population, taking into account a comprehensive list of risk factors, including high-sensitivity C-reactive protein (hs-CRP). Our findings suggest that elevated serum resistin concentration is a significant risk factor for ischemic stroke in a general Japanese population.

\section{Methods \\ Study population}

In 2002, a screening survey for the present study was performed in the town of Hisayama, a suburb of the Fukuoka metropolitan area in Japan. The age and occupational distributions and nutrient intake of the population were almost identical to those of Japan as a whole based on data from the national census and nutrition survey. A detailed description of this survey was published previously [15]. Briefly, of all residents aged 40 years or over, 3,328 underwent the examination (participation rate, $77.6 \%$ ). After excluding 30 subjects who did not consent to participate in the study, 86 who had already eaten breakfast, and 11 who did not have enough stored sera with which to measure resistin concentrations, a total of 3,201 (1,382 men and 1,819 women) were enrolled in the study group and underwent a comprehensive assessment. This study was approved by the Ethics Committee of Kyushu University, and written informed consent was obtained from all participants.

\section{Definition of cardiovascular disease}

Cases of CVD were defined as subjects who had histories of stroke or coronary heart disease. CVD was identified using the following criteria. The diagnosis and classification of stroke were determined on the basis of clinical information, including brain computed tomography and magnetic resonance imaging, cerebral angiography, echocardiography or carotid duplex imaging. Stroke was defined as sudden onset of nonconvulsive and focal neurological deficit persisting for $\geq 24$ hours and was classified as either ischemic or hemorrhagic $[16,17]$. Hemorrhagic stroke included brain hemorrhage and subarachnoid hemorrhage. Ischemic stroke was further divided into 4 clinical categories -- lacunar infarction, atherothrombotic infarction, cardioembolic infarction, and undetermined subtype of ischemic stroke -- based on the Classification of Cerebrovascular Disease III proposed by the National Institute of Neurological Disorders and Stroke [18], as well as on the basis of the diagnostic criteria of the Trial of Org10172 in Acute Stroke Treatment Study [19] and the Cerebral Embolism Task Force [20]. Details of the diagnostic criteria for the ischemic stroke subtypes have been described previously [21]. In brief, lacunar infarction was defined as the presence of a relevant brainstem, basal ganglia, or subcortical hemispheric lesion with a diameter of $<1.5 \mathrm{~cm}$ demonstrated by brain imaging, and no evidence of cerebral cortical or cerebellar impairment. Atherothrombotic infarction was diagnosed when the subjects had significant stenosis (>50\%) or occlusion of a major cerebral artery with an infarct $\geq 1.5 \mathrm{~cm}$ in a brain imaging study. The diagnosis of cardioembolic infarction was made on the basis of primary and secondary clinical features suggestive of cardioembolic infarction as reported by the Cerebral Embolism Task Force [20]. The undetermined subtype of ischemic stroke included strokes that could not be classified because of insufficient clinical or morphologic information. We considered morphologic findings to be significant and used clinical features as reference information. Cases of cerebrovascular diseases that could be attributed to a distinct pathology, such as collagen disease, hematological disorder, trauma, chronic subdural hematoma, or moyamoya disease, were excluded from the evaluation.

The diagnostic criteria for coronary heart disease included acute myocardial infarction, silent myocardial infarction or coronary artery disease followed by coronary artery bypass surgery or angioplasty $[16,17]$. Acute myocardial infarction was diagnosed when a subject met at least two of the following criteria: (1) typical symptoms, including prolonged severe anterior chest pain; (2) abnormal elevation in cardiac enzymes, i.e., greater than a two-fold increase in the upper limit of the normal range; (3) evolving diagnostic electrocardiogram (ECG) changes; and, (4) morphological changes, including local asynergy of car- 
diac wall motion on echocardiography or persistent perfusion defects observed using cardiac scintigraphy. Silent myocardial infarction was defined as the above-mentioned morphological changes without any history of clinical symptoms or abnormalities in cardiac enzymes. Among the participants, 175 subjects had a history of CVD as follows: 79 had ischemic stroke; 41 had hemorrhagic stroke; 42 had coronary heart disease; 11 had both ischemic stroke and coronary heart disease; and, 2 had hemorrhagic stroke and coronary heart disease. In the analysis stratified by type of CVD, coexisting CVDs were each stratified into their respective types. Furthermore, on the basis of the above criteria, 90 ischemic stroke cases were divided into 51 cases of lacunar infarction, 29 of atherothrombotic infarction, 7 of cardioembolic infarction, and 3 of undetermined infarction; 43 hemorrhagic stroke cases were divided into 31 of brain hemorrhage and 12 of subarachnoid hemorrhage.

\section{Measurement of serum resistin concentrations}

At the screening examination, blood samples were obtained between 8:00 and 10:30 AM after at least a 12hour overnight fast. An aliquot of serum from each subject was stored at $-80^{\circ} \mathrm{C}$. Serum resistin was measured using a human ELISA kit (R\&D Systems, Inc., Minneapolis, MN) following the manufacturer's protocol. According to data supplied by the manufacturer, the limit of detection was $0.16 \mathrm{ng} / \mathrm{ml}$, and the intra-assay coefficient of variations (CVs) were $<5 \%$ for low concentrations, and $<4 \%$ for high concentrations. The inter-assay $\mathrm{CV}$ was $<9 \%$ for both low and high concentrations. Recovery was greater than $90 \%$. We confirmed that linearity was maintained at concentrations less than $0.16 \mathrm{ng} / \mathrm{ml}$, and both intra- and inter-assay CVs were comparable to those specified by the manufacturer (2.6-10.5\%). The antibodies used in the enzyme-linked immunosorbent assay (ELISA) do not cross-react with either mouse resistin or other human cytokines. The results obtained using the ELISA manufactured by R\&D were highly correlated with those obtained previously using a kit supplied by LINCO (Linco Research, Inc., St. Charles, MO) $(\mathrm{r}=0.987, \mathrm{y}=$ $1.040 \mathrm{x}+0.469, \mathrm{y}$, this kit, $\mathrm{x}$, LINCO's kit) [22-24].

\section{Measurement of confounding factors}

Blood for the glucose assay was collected into tubes containing $\mathrm{NaF}$, and plasma glucose concentrations were determined immediately after venipuncture using the glucose-oxidase method. Serum total cholesterol and high density lipoprotein (HDL) cholesterol concentrations were determined enzymatically. hs-CRP concentrations were measured using a modification of the Behring LatexEnhanced CRP assay on a Behring Nephelometer BN-100 (Behring Diagnostics, Westwood, MA). Blood pressure was measured three times using a standard mercury sphygmomanometer in the seated position after the sub- ject had rested for at least 5 minutes. ECG abnormalities were defined as left ventricular hypertrophy (Minnesota Code 3-1) and/or ST depression (Minnesota Code 4-1, 2, $3)$.

Body height and weight were measured in light clothing without shoes, and body mass index (BMI) was calculated. Each participant completed a self-administered questionnaire that assessed medical history, smoking habits, alcohol intake, and exercise. The questionnaire was checked by trained interviewers at the screening. Alcohol intake and smoking habits were classified as either presence or absence of current habitual use. Those subjects who engaged in sports or other forms of exercise $\geq 3$ times a week during their leisure time categorized regular exercisers.

\section{Statistical analysis}

The SAS software package version 8.2 (SAS Institute, Inc., Cary, NC) was used to perform all statistical analyses. The subjects were divided into quintiles of resistin concentration as follows: $<6.8,6.8$ to $8.7,8.8$ to $11.5,11.6$ to 16.2 , and $\geq 16.3 \mathrm{ng} / \mathrm{ml}$. Values of possible risk factors were adjusted for age and sex using the covariance method and were compared among the quintiles using the linear regression model. Age- and sex-adjusted resistin concentrations were compared among CVD subtypes using the same methods. The frequencies of risk factors were adjusted for age and sex by the direct method using all subjects as a standard population and were tested for trends using the Cochran-Mantel-Haenszel test. Age- and sex-adjusted or multivariate-adjusted odds ratios (ORs) and $95 \%$ confidence intervals (CIs) for CVD were calculated using logistic regression analysis. A p-value $<0.05$ was considered statistically significant in all analyses.

\section{Results \\ Clinical characteristics of subjects}

Age- and sex-adjusted means or frequencies of potential risk factors by quintiles of serum resistin concentration are shown in Table 1. Age and hs-CRP, and the frequency of male sex increased with quintiles of resistin, while mean HDL-cholesterol and the frequencies of alcohol consumption and regular exercise were negatively associated with the quintiles of resistin. The other variables were not significantly associated with resistin quintiles.

\section{Serum resistin concentrations by cardiovascular disease}

Age- and sex-adjusted serum resistin concentrations were greater in subjects with total CVD than in those without CVD ( $p=0.002)$ (Table 2). When CVD was divided into types, subjects with ischemic stroke had greater resistin concentrations than those without CVD ( $p<0.001)$. Regarding subtypes of ischemic stroke, subjects with lacunar and atherothrombotic infarction had greater resistin 
Table I: Age- and sex-adjusted means or frequencies of cardiovascular risk factors according to serum resistin quintiles.

\begin{tabular}{|c|c|c|c|c|c|c|}
\hline \multirow[b]{2}{*}{ Variables } & \multicolumn{6}{|c|}{ Serum resistin level $(\mathrm{ng} / \mathrm{ml})$} \\
\hline & $\begin{array}{c}1.5-6.7 \\
(n=648)\end{array}$ & $\begin{array}{c}6.8-8.7 \\
(n=633)\end{array}$ & $\begin{array}{c}8.8-1 I .5 \\
(n=64 I)\end{array}$ & $\begin{array}{l}11.6-16.2 \\
(n=636)\end{array}$ & $\begin{array}{l}16.3-90.2 \\
(n=643)\end{array}$ & $P$ value for trend \\
\hline Age (years) & $\begin{array}{c}59 \\
\text { (II) }\end{array}$ & $\begin{array}{l}61 \\
(12)\end{array}$ & $\begin{array}{l}61 \\
(12)\end{array}$ & $\begin{array}{l}62 \\
(13)\end{array}$ & $\begin{array}{l}64 \\
(14)\end{array}$ & $<0.001$ \\
\hline Men (\%) & 39.2 & 38.7 & 40.6 & 46.2 & 51.2 & $<0.001$ \\
\hline BMI $\left(\mathrm{kg} / \mathrm{m}^{2}\right)$ & $\begin{array}{l}23.1 \\
(3.4)\end{array}$ & $\begin{array}{l}23.2 \\
(3.4)\end{array}$ & $\begin{array}{l}22.9 \\
(3.4)\end{array}$ & $\begin{array}{l}23.1 \\
(3.4)\end{array}$ & $\begin{array}{l}23.1 \\
(3.4)\end{array}$ & 0.69 \\
\hline Fasting plasma glucose (mmol/l) & $\begin{array}{l}6.1 \\
(1.3)\end{array}$ & $\begin{array}{l}6.1 \\
(1.3)\end{array}$ & $\begin{array}{l}6.0 \\
(1.3)\end{array}$ & $\begin{array}{l}6.1 \\
(1.3)\end{array}$ & $\begin{array}{l}6.0 \\
(1.3)\end{array}$ & 0.55 \\
\hline Diabetes (\%) & 13.7 & 13.8 & 11.2 & 14.8 & 14.3 & 0.82 \\
\hline Total cholesterol $(\mathrm{mmol} / \mathrm{l})$ & $\begin{array}{c}5.25 \\
(0.89)\end{array}$ & $\begin{array}{c}5.22 \\
(0.89)\end{array}$ & $\begin{array}{c}5.27 \\
(0.89)\end{array}$ & $\begin{array}{c}5.27 \\
(0.89)\end{array}$ & $\begin{array}{c}5.19 \\
(0.90)\end{array}$ & 0.51 \\
\hline HDL-cholesterol (mmol/l) & $\begin{array}{l}1.70 \\
(0.40)\end{array}$ & $\begin{array}{l}1.61 \\
(0.39)\end{array}$ & $\begin{array}{l}1.60 \\
(0.39)\end{array}$ & $\begin{array}{l}1.60 \\
(0.39)\end{array}$ & $\begin{array}{l}1.53 \\
(0.40)\end{array}$ & $<0.001$ \\
\hline High sensitivity C-reactive protein (mg/l) & $\begin{array}{c}0.43 \\
(0.04-4.53)\end{array}$ & $\begin{array}{c}0.49 \\
(0.05-5.06)\end{array}$ & $\begin{array}{c}0.54 \\
(0.05-5.53)\end{array}$ & $\begin{array}{c}0.55 \\
(0.05-5.64)\end{array}$ & $\begin{array}{c}0.68 \\
(0.07-7.18)\end{array}$ & $<0.001$ \\
\hline Systolic blood pressure $(\mathrm{mmHg})$ & $\begin{array}{l}132 \\
(20)\end{array}$ & $\begin{array}{l}133 \\
(20)\end{array}$ & $\begin{array}{l}131 \\
(20)\end{array}$ & $\begin{array}{l}132 \\
(20)\end{array}$ & $\begin{array}{l}132 \\
(20)\end{array}$ & 0.65 \\
\hline Diastolic blood pressure $(\mathrm{mmHg})$ & $\begin{array}{l}79 \\
(12)\end{array}$ & $\begin{array}{l}79 \\
(12)\end{array}$ & $\begin{array}{c}78 \\
(12)\end{array}$ & $\begin{array}{l}79 \\
(12)\end{array}$ & $\begin{array}{c}78 \\
(12)\end{array}$ & 0.38 \\
\hline Antihypertensive medication (\%) & 21.7 & 28.2 & 22.1 & 22.8 & 26.2 & 0.52 \\
\hline Hypertension (\%) & 44.4 & 46.6 & 39.6 & 43.6 & 47.2 & 0.67 \\
\hline Electrocardiographic abnormalities (\%) & 15.1 & 16.1 & 15.8 & 14.9 & 16.1 & 0.47 \\
\hline Current drinking (\%) & 50.9 & 45.1 & 40.8 & 42.1 & 37.1 & $<0.001$ \\
\hline Current smoking (\%) & 20.9 & 20.2 & 22.7 & 20.3 & 24.7 & 0.14 \\
\hline Regular exercise (\%) & 11.6 & 11.0 & 10.8 & 8.4 & 9.5 & 0.04 \\
\hline
\end{tabular}

BMI: body mass index; HDL: high density lipoprotein. All values are given as mean (standard deviation) or as percentages.

C-reactive protein is shown by geometric mean and $95 \%$ confidence intervals due to the skewed distribution. Age and percent of men are not adjusted.

Table 2: Age- and sex-adjusted resistin values according to types of cardiovascular disease.

\begin{tabular}{lccc}
\hline & Number & $\begin{array}{c}\text { Age- and sex- } \\
\text { adjusted resistin } \\
\text { values (ng/ml) }\end{array}$ & P vs. no cardiovascular disease cases \\
\hline No cardiovascular disease & 3,026 & $10.3(3.8-28.0)$ & - \\
Cardiovascular disease & 175 & $11.7(4.2-32.4)$ & 0.002 \\
$\quad$ Ischemic stroke & 90 & $13.0(4.7-35.7)$ & 0.001 \\
$\quad$ Lacunar infarction & 51 & $12.1(4.4-32.9)$ & 0.02 \\
$\quad$ Atherothrombotic infarction & 29 & $16.3(6.0-44.4)$ & 0.001 \\
$\quad$ Cardioembolic infarction & 7 & $11.5(4.2-31.0)$ & 0.14 \\
$\quad$ Undetermined infarction & 3 & $6.7(1.7-18.0)$ & 0.90 \\
Hemorrhagic stroke & 43 & $10.3(3.8-28.1)$ & 0.37 \\
$\quad$ Brain hemorrhage & 31 & $11.1(4.1-30.2)$ & 0.22 \\
$\quad$ Subarachnoid hemorrhage & 12 & $8.6(3.2-23.2)$ & 0.14 \\
Coronary heart disease & 55 & $11.3(4.1-31.0)$ & \\
\hline
\end{tabular}

Resistin is shown by geometric mean and $95 \%$ confidenceintervals due to the skewed distribution. 
than subjects without CVD ( $\mathrm{p}=0.02$ for lacunar infarction; $\mathrm{p}<0.001$ for atherothrombotic infarction); however, no association was observed between resistin and cardioembolic infarction or undetermined subtype of ischemic stroke. Resistin concentrations in subjects with hemorrhagic stroke, including brain and subarachnoid hemorrhage, and coronary heart disease were not different from subjects without CVD.

\section{Association of resistin concentrations with cardiovascular disease}

To further evaluate the association between serum resistin concentrations and the risk of CVD, age- and sex-adjusted or multivariate-adjusted ORs were estimated by quintiles of resistin concentration (Table 3 ). In Model 1, the ageand sex-adjusted ORs for total CVD and ischemic stroke increased with quintile of serum resistin ( $\mathrm{p}$ for trends, 0.02 for CVD, $<0.001$ for ischemic stroke). Compared to the first quintile, the age- and sex-adjusted OR for ischemic stroke was greater in the third, fourth, and fifth quintiles (the third quintile: OR 3.54, 95\%CI 1.17-10.67, $\mathrm{p}=0.02$; the fourth quintile: OR 4.48, 95\%CI 1.53-13.09, $\mathrm{p}=0.006$; the fifth quintile: OR 4.70, 95\%CI 1.62-13.61, $\mathrm{p}=0.004$ ), while there was no association between quintile of resistin and CVD. The association between quintile of resistin and ischemic stroke remained significant even after adjustment for age, sex, BMI, diabetes, total cholesterol, HDL-cholesterol, systolic blood pressure, ECG abnormalities, current drinking, current smoking, and regular exercise (Model 2). Furthermore, as shown in Model 3, after adjustment for hs-CRP and the confounding factors, this association remained essentially unchanged (Fig. 1). No significant associations were found between quintile of resistin and either hemorrhagic stroke or coronary heart disease.

\section{Combined effects of high serum resistin with other risk factors}

To determine whether high serum resistin concentration was associated with increased risk of ischemic stroke in subjects who had either diabetes or hypertension, we examined the combined and unique effects of high resis-

Table 3: Age- and sex- or multivariate-adjusted odds ratios for cardiovascular diseases according to serum resistin quintiles.

\begin{tabular}{|c|c|c|c|c|c|c|}
\hline & \multicolumn{6}{|c|}{ Serum resistin level (ng/ml) } \\
\hline & I.5-6.7 & 6.8-8.7 & $8.8-11.5$ & | I.6- | 6.2 & 16.3-90.2 & $P$ value for trend \\
\hline No cardiovascular disease, $\mathrm{n}$ & 628 & 610 & 604 & 595 & 589 & \\
\hline Cardiovascular disease, $\mathrm{n}$ & 20 & 23 & 37 & 41 & 54 & \\
\hline Model I-adjusted OR $(95 \% \mathrm{CI})$ & $\begin{array}{c}\text { I } \\
\text { (referent) }\end{array}$ & $\begin{array}{c}0.95 \\
(0.51-1.76)\end{array}$ & $\begin{array}{c}1.55 \\
(0.88-2.74)\end{array}$ & $\begin{array}{c}|.5| \\
(0.86-2.64)\end{array}$ & $\begin{array}{c}1.64 \\
(0.95-2.84)\end{array}$ & 0.02 \\
\hline Model 2-adjusted OR $(95 \% \mathrm{Cl})$ & I & $\begin{array}{c}0.88 \\
(0.47-1.66)\end{array}$ & $\begin{array}{c}1.56 \\
(0.88-2.77)\end{array}$ & $\begin{array}{c}1.39 \\
(0.79-2.45)\end{array}$ & $\begin{array}{c}1.52 \\
(0.87-2.66)\end{array}$ & 0.04 \\
\hline Model 3-adjusted OR (95\% Cl) & $\begin{array}{c}\text { I } \\
\text { (referent) }\end{array}$ & $\begin{array}{c}0.87 \\
(0.46-1.63)\end{array}$ & $\begin{array}{c}1.53 \\
(0.86-2.72)\end{array}$ & $\begin{array}{c}1.36 \\
(0.77-2.4 \mathrm{I})\end{array}$ & $\begin{array}{c}1.47 \\
(0.84-2.58)\end{array}$ & 0.06 \\
\hline Ischemic stroke, n & 4 & II & 17 & 25 & 33 & \\
\hline Model I-adjusted OR $(95 \% \mathrm{Cl})$ & $\begin{array}{c}\text { I } \\
\text { (referent) }\end{array}$ & $\begin{array}{c}2.21 \\
(0.70-7.05)\end{array}$ & $\begin{array}{c}3.54 \\
(1.17-10.67)\end{array}$ & $\begin{array}{c}4.48 \\
(1.53-13.09)\end{array}$ & $\begin{array}{c}4.70 \\
(1.62-13.61)\end{array}$ & $<0.001$ \\
\hline Model 2-adjusted OR $(95 \% \mathrm{Cl})$ & $\begin{array}{c}\text { I } \\
\text { (referent) }\end{array}$ & $\begin{array}{c}1.94 \\
(0.60-6.23)\end{array}$ & $\begin{array}{c}3.36 \\
(1.11-10.22)\end{array}$ & $\begin{array}{c}3.87 \\
(1.31-11.39)\end{array}$ & $\begin{array}{c}3.97 \\
(1.36-11.61)\end{array}$ & 0.002 \\
\hline Model 3-adjusted OR $(95 \% \mathrm{Cl})$ & (referent) & $\begin{array}{c}1.84 \\
(0.57-5.96)\end{array}$ & $\begin{array}{c}3.26 \\
(1.07-9.92)\end{array}$ & $\begin{array}{c}3.66 \\
(1.24-10.79)\end{array}$ & $\begin{array}{c}3.59 \\
(1.22-10.55)\end{array}$ & 0.006 \\
\hline Hemorrhagic stroke, n & 9 & 7 & 9 & 7 & II & \\
\hline Model I-adjusted OR $(95 \% \mathrm{Cl})$ & $\begin{array}{c}\text { I } \\
\text { (referent) }\end{array}$ & $\begin{array}{c}0.70 \\
(0.26-1.92)\end{array}$ & $\begin{array}{c}0.93 \\
(0.36-2.37)\end{array}$ & $\begin{array}{c}0.66 \\
(0.24-1.80)\end{array}$ & $\begin{array}{c}0.89 \\
(0.36-2.23)\end{array}$ & 0.83 \\
\hline Model 2-adjusted OR (95\% Cl) & I & $\begin{array}{c}0.70 \\
(0.26-1.92)\end{array}$ & $\begin{array}{c}1.02 \\
(0.39-2.64)\end{array}$ & $\begin{array}{c}0.70 \\
(0.25-1.93)\end{array}$ & $\begin{array}{c}0.98 \\
(0.38-2.50)\end{array}$ & 0.99 \\
\hline Model 3-adjusted OR (95\% Cl) & (referent) & $\begin{array}{c}0.69 \\
(0.25-1.90)\end{array}$ & $\begin{array}{c}1.00 \\
(0.39-2.60)\end{array}$ & $\begin{array}{c}0.69 \\
(0.25-1.90)\end{array}$ & $\begin{array}{c}0.96 \\
(0.37-2.46)\end{array}$ & 0.97 \\
\hline Coronary heart disease, $\mathrm{n}$ & 9 & 6 & 12 & II & 17 & \\
\hline Model I-adjusted OR $(95 \% \mathrm{CI})$ & $\begin{array}{c}\text { I } \\
\text { (referent) }\end{array}$ & $\begin{array}{c}0.55 \\
(0.19-1.57)\end{array}$ & $\begin{array}{c}1.13 \\
(0.47-2.73)\end{array}$ & $\begin{array}{c}0.88 \\
(0.36-2.18)\end{array}$ & $\begin{array}{c}\text { I.II } \\
(0.48-2.59)\end{array}$ & 0.48 \\
\hline Model 2-adjusted OR (95\% Cl) & (referent) & $\begin{array}{c}0.48 \\
(0.16-1.4 I)\end{array}$ & $\begin{array}{c}1.20 \\
(0.49-2.95)\end{array}$ & $\begin{array}{c}0.79 \\
(0.31-1.99)\end{array}$ & $\begin{array}{c}1.05 \\
(0.44-2.50)\end{array}$ & 0.53 \\
\hline Model 3-adjusted OR $(95 \% \mathrm{Cl})$ & I & $\begin{array}{c}0.49 \\
(0.17-1.42)\end{array}$ & $\begin{array}{c}1.21 \\
(0.49-2.97)\end{array}$ & $\begin{array}{c}0.80 \\
(0.32-2.02)\end{array}$ & $\begin{array}{c}1.09 \\
(0.45-2.59)\end{array}$ & 0.49 \\
\hline
\end{tabular}

OR: odds ratio; $\mathrm{Cl}$ : confidence interval. Model I: adjustment was made for age and sex; Model 2: adjustment was made for age, sex, body mass index, diabetes, total cholesterol, HDL cholesterol, systolic blood pressure, electrocardiographic abnormalities, current drinking, current smoking, and regular exercise; Model 3: adjustment was made for the variables used in Model 2 and for high sensitivity $C$-reactive protein. 


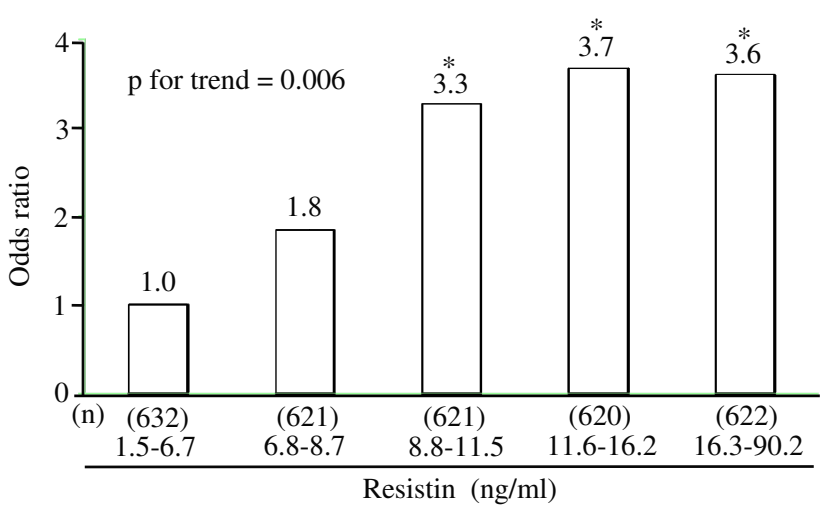

Figure I

Multivariate-adjusted odds ratio for the presence of ischemic stroke according to quintiles of serum resistin concentrations. The OR compared to the first quintile is shown. Multivariate adjustment was made for age, sex, body mass index, diabetes, total cholesterol, high density lipoprotein cholesterol, high sensitivity C-reactive protein, systolic blood pressure, electrocardiographic abnormalities, current drinking, current smoking and regular exercise. *, $\mathrm{p}<$ 0.05 compared to the first quartile.

tin and the presence of either diabetes or hypertension on the risk of ischemic stroke. High resistin was defined as the third, fourth, and fifth quintile of resistin concentration. Compared to non-diabetic subjects with low resistin, the age- and sex-adjusted OR of ischemic stroke was greater in non-diabetic subjects with high resistin (OR: 2.15; 95\% CI: 1.13-4.10; $\mathrm{p}=0.02)$, but not in diabetic subjects with low resistin (OR: 1.27; 95\% CI: 0.35-4.62; p $=0.72$ ). The risk of ischemic stroke markedly increased in diabetic subjects with high resistin (OR: 5.88; 95\% CI: 2.82-12.26; $\mathrm{p}<0.001)$. Furthermore, diabetic subjects with high resistin had greater risk of ischemic stroke than diabetic subjects with low resistin $(\mathrm{p}<0.05)$. Similarly, a marked increase in the age- and sex-adjusted risk of ischemic stroke was observed in hypertensive subjects with high resistin compared with normotensive subjects with low resistin (OR: 4.66; 95\% CI: 1.81-11.97; p = 0.001 ), but not in normotensive subjects with high resistin (OR: 1.87 ; 95\%CI: 0.69-5.10; $\mathrm{p}=0.22$ ), or hypertensive subjects with low resistin (OR: 1.52; 95\%CI: 0.514.54; $\mathrm{p}=0.45$ ). In hypertensive subjects, high resistin was associated with risk of ischemic stroke $(\mathrm{p}<0.05)$. These associations remained robust even after adjustment for the above-mentioned confounding factors (Fig. 2).

\section{Discussion}

Our large cross-sectional data set representative of the general Japanese population demonstrated that serum resistin concentrations were greater in subjects with ischemic stroke, especially in those with lacunar and
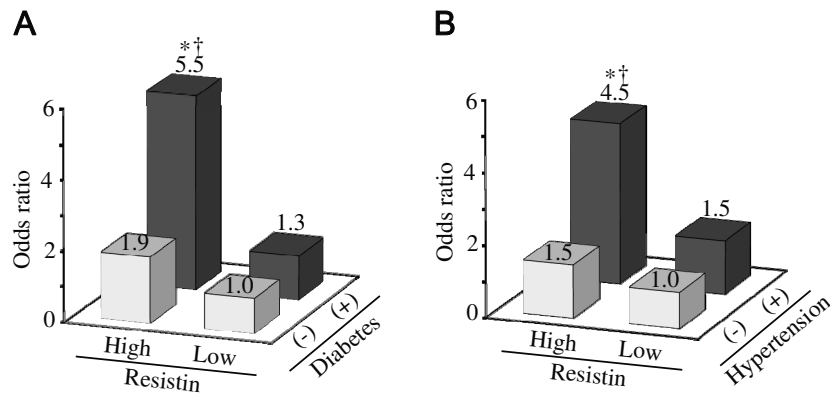

Figure 2

Multivariate-adjusted odds ratios for ischemic stroke according to the presence or absence of high serum resistin concentrations and either diabetes or hypertension. Multivariate adjustment was made as described in the legend of Fig. I, but each risk factor that had been used for categorization was excluded from the confounding factors. High resistin was defined as the third, fourth, and fifth quintile of resistin concentration. A. Diabetes (DM). The OR compared to the reference (DM (-) + low resistin) is shown. *, OR $=5.54(95 \% \mathrm{Cl}, 2.60-1 \mathrm{l} .76), \mathrm{p}<0.00 \mathrm{I}$ for DM $(+)+$ high resistin. $\mathrm{OR}=1.87(95 \% \mathrm{Cl}, 0.97-3.59), \mathrm{p}=0.06$, for DM (-) + high resistin; OR = I.25 $(95 \% \mathrm{Cl}, 0.34-4.64), \mathrm{P}=$ 0.73 for DM $(+)+$ low resistin. $\dagger, p<0.05$ compared to DM $(+)+$ low resistin. B. Hypertension (HT). OR compared to the reference $(\mathrm{HT}(-)+$ low resistin) is shown. *, OR=4.46 (95\% Cl, I.7I-I I.62), $\mathrm{P}=0.002$ for $\mathrm{HT}(+)+$ high resistin. $\mathrm{OR}=1.47(95 \% \mathrm{Cl}, 0.53-4.08), \mathrm{p}=0.45$, for HT $(-)+$ high resistin; $\mathrm{OR}=1.48(95 \% \mathrm{Cl}, 0.49-4.53), \mathrm{p}=0.49$ for $\mathrm{HT}(+)$ + low resistin. $\dagger, \mathrm{p}<0.05$ compared to $\mathrm{HT}(+)+$ low resistin.

atherothrombotic infarction. Elevated resistin was an independent risk factor for ischemic stroke even after adjustment for confounding factors including hs-CRP. In the stratified analyses, the combination of high resistin and either diabetes or hypertension markedly increased the risk of ischemic stroke.

In our study, subjects with lacunar and atherothrombotic infarction, but not cardioembolic infarction, had greater resistin concentrations. In particular, in subjects who had suffered atherothrombotic infarction, serum resistin was dramatically elevated. Atherothrombotic infarction is caused by atherosclerotic lesions of large vessels, while lacunar infarcts occur as a result of multiple mechanisms: 1) lipohyalinosis and/or fibrinoid necrosis; 2 ) microatheroma; 3 ) atherosclerosis of the basilar and middle cerebral artery stem or proximal division of large vessels; or, 4) cardioembolic occlusion [25]. Lipohyalinosis is a vasculopathy caused by hypertension [25]. In contrast, large vessel atherosclerosis is associated with traditional risk factors and inflammation, while cardioembolism seems less related to atherosclerosis. Thus, our findings regarding the association between each subtype of ischemic stroke and serum resistin is reasonably consistent with the 
known pathology. Most recently, Tsukahara et al. reported that serum resistin levels in individuals with diabetes who had a history of stroke were higher than those without in a case/control study of Japanese [26]. However, a recent nested case-control epidemiological study of Europeans showed that elevated resistin concentration was not a predictor of ischemic stroke [14]. This inconsistency might be caused by differences in study design and ethnicity. Although the European study lacked information on ischemic stroke subtype, in general, the prevalence of cardioembolic infarction, which is a potentially fatal disease and weakly associated with atherosclerosis in brain vessels, may be greater in prospective design than in crosssectional design. In addition, Caucasians are at a greater risk of cardioembolic infarction compared with Japanese individuals $[16,27,28]$.

The present study showed that the association between circulating resistin and ischemic stroke was independent of hs-CRP and other confounding factors. Resistin could directly stimulate expression of pro-inflammatory cytokines such as tumor necrosis factor- $\alpha$, interleukin- 6 in human peripheral blood mononuclear cells [29] and increase vascular cell adhesion molecule- 1 and intracellular adhesion molecule-1 gene expression in vascular endothelial cells [7]. A recent clinical study showed that the association between plasma resistin and monocyte chemoattractant protein-1 was independent of hs-CRP and other confounding factors [30]. Therefore, resistin could potentiate vascular inflammation and atherogenesis.

Our previous studies demonstrated that serum resistin was tightly correlated with a single nucleotide polymorphism (SNP) at -420 of the human resistin gene, namely, resistin was highest in individuals with the $\mathrm{G} / \mathrm{G}$ genotype, followed by the $\mathrm{C} / \mathrm{G}$ and $\mathrm{C} / \mathrm{C}$ genotypes [22-24]. It was reported that Japanese individuals with the $\mathrm{C} / \mathrm{G}$ or $\mathrm{G} / \mathrm{G}$ genotypes of SNP-420 were more likely to have had a stroke than those with the $\mathrm{C} / \mathrm{C}$ genotype [26]. A clinical study of Finns found that the $\mathrm{G} / \mathrm{G}$ genotype was associated with cerebrovascular disease [31]. Thus, resistin may directly contribute to ischemic stroke.

In the present study, serum resistin was not associated with hemorrhagic stroke or coronary heart disease. To our knowledge, there are no published studies that examined the relationship between resistin and hemorrhagic stroke. Regarding coronary heart disease, reported findings have been highly controversial; some epidemiological and clinical studies showed a significant association between elevated resistin and coronary heart disease [13,14], whereas, in other studies, this association was not observed $[11,12]$. Further investigations, especially those involving a larger number of samples, are necessary to clarify the role of resistin in the development of hemorrhagic stroke and coronary artery disease.

The present study has three limitations that should be mentioned. First, due to the cross-sectional design, we cannot exclude the possibility that hyperresistinemia was a consequence of ischemic stroke. Prospective studies are required to address this critical question. Second, the number of subjects with ischemic stroke was relatively small, although we used a highly accurate method of detecting and classifying all cases. Likewise, the lack of association between either hemorrhagic stroke or coronary heart disease and serum resistin may be reflection of the small samples. Third, since hemorrhagic stroke and coronary heart disease both have high mortality, survival bias could partly explain why no association was found between these diseases and serum resistin. Thus, the generalizability of the study results may be somewhat limited.

\section{Conclusion}

Serum resistin concentration was a risk factor for ischemic stroke, especially lacunar and atherothrombotic infarction, and the association was independent of traditional confounding factors and hs-CRP. Furthermore, the combination of high resistin concentration and the presence of either diabetes or hypertension markedly increased the risk of ischemic stroke. The mechanism by which resistin induces ischemic stroke in humans and how resistin interacts with diabetes or hypertension to further increase the risk of ischemic stroke remain unclear. Further studies are required to clarify these issues.

\section{Competing interests}

The authors declare that they have no competing interests.

\section{Authors' contributions}

$\mathrm{HO}, \mathrm{YD}, \mathrm{HM}$, and YK designed the study and directed its implementation, including quality assurance and control. TN and KY designed the study's analytic strategy. MI helped supervise the field activities. RK, JH, and YT helped conduct the literature review. All authors read and approved the final manuscript.

\section{Acknowledgements}

This study was supported in part by a Grant-in-Aid for Scientific Research C (No. 20591063) from the Ministry of Education, Culture, Sports, Science and Technology of Japan, and a grant from Ehime University. The authors thank the staff of the Division of Health and Welfare of Hisayama for their cooperation in this study.

\section{References}

I. Steppan CM, Lazar MA: The current biology of resistin. J Intern Med 2004, 255(4):439-447.

2. Kim KH, Lee K, Moon YS, Sul HS: A cysteine-rich adipose tissuespecific secretory factor inhibits adipocyte differentiation. J Biol Chem 200I, 276( I 4): I I 252-I I 256.

3. Rajala MW, Qi Y, Patel HR, Takahashi N, Banerjee R, Pajvani UB, Sinha MK, Gingerich RL, Scherer PE, Ahima RS: Regulation of resis- 
tin expression and circulating levels in obesity, diabetes, and fasting. Diabetes 2004, 53(7):167|-1679.

4. Steppan CM, Bailey ST, Bhat S, Brown EJ, Banerjee RR, Wright CM, Patel HR, Ahima RS, Lazar MA: The hormone resistin links obesity to diabetes. Nature 200I, 409(68 I8):307-3I2.

5. Patel L, Buckels AC, Kinghorn IJ, Murdock PR, Holbrook JD, Plumpton $\mathrm{C}$, Macphee $\mathrm{CH}$, Smith SA: Resistin is expressed in human macrophages and directly regulated by PPAR gamma activators. Biochem Biophys Res Commun 2003, 300(2):472-476.

6. Calabro P, Samudio I, Willerson JT, Yeh ET: Resistin promotes smooth muscle cell proliferation through activation of extracellular signal-regulated kinase $\mathrm{I} / 2$ and phosphatidylinositol 3-kinase pathways. Circulation 2004, I I 0(21):3335-3340.

7. Verma S, Li SH, Wang CH, Fedak PW, Li RK, Weisel RD, Mickle DA: Resistin promotes endothelial cell activation: further evidence of adipokine-endothelial interaction. Circulation 2003, 108(6):736-740.

8. Bo S, Gambino R, Pagani A, Guidi S, Gentile L, Cassader M, Pagano GF: Relationships between human serum resistin, inflammatory markers and insulin resistance. Int J Obes (Lond) 2005 , 29(II):|3|5-1320.

9. Kunnari A, Ukkola O, Paivansalo M, Kesaniemi YA: High plasma resistin level is associated with enhanced highly sensitive $C$ reactive protein and leukocytes. J Clin Endocrinol Metab 2006 , 9I(7):2755-2760.

10. Shetty GK, Economides PA, Horton ES, Mantzoros CS, Veves A: Circulating adiponectin and resistin levels in relation to metabolic factors, inflammatory markers, and vascular reactivity in diabetic patients and subjects at risk for diabetes. Diabetes Care 2004, 27(10):2450-2457.

11. Lim S, Koo BK, Cho SW, Kihara S, Funahashi T, Cho YM, Kim SY, Lee HK, Shimomura I, Park KS: Association of adiponectin and resistin with cardiovascular events in Korean patients with type 2 diabetes: the Korean atherosclerosis study (KAS): a 42month prospective study. Atherosclerosis 2008, 196(I):398-404.

12. Pilz $S$, Weihrauch $G$, Seelhorst $U$, Wellnitz B, Winkelmann BR, Boehm BO, Marz W: Implications of resistin plasma levels in subjects undergoing coronary angiography. Clin Endocrinol (Oxf) 2007, 66(3):380-386.

13. Reilly MP, Lehrke M, Wolfe ML, Rohatgi A, Lazar MA, Rader DJ: Resistin is an inflammatory marker of atherosclerosis in humans. Circulation 2005, I I I(7):932-939.

14. Weikert C, Westphal S, Berger K, Dierkes J, Mohlig M, Spranger J Rimm EB, Willich SN, Boeing H, Pischon T: Plasma resistin levels and risk of myocardial infarction and ischemic stroke. I Clin Endocrinol Metab 2008, 93(7):2647-2653.

15. Doi $Y$, Kubo M, Yonemoto K, Ninomiya T, Iwase M, Arima $H$, Hata J, Tanizaki Y, lida M, Kiyohara Y: Fasting plasma glucose cutoff for diagnosis of diabetes in a Japanese population. J Clin Endocrinol Metab 2008, 93(9):3425-3429.

16. Kubo M, Kiyohara Y, Ninomiya T, Tanizaki Y, Yonemoto K, Doi $Y$, Hata J, Oishi Y, Shikata K, lida M: Decreasing incidence of lacunar vs other types of cerebral infarction in a Japanese population. Neurology 2006, 66(10):1539-1544.

17. Kubo M, Kiyohara Y, Kato I, Tanizaki Y, Arima H, Tanaka K, Nakamura $\mathrm{H}$, Okubo $\mathrm{K}$, lida $\mathrm{M}$ : Trends in the incidence, mortality, and survival rate of cardiovascular disease in a Japanese community: the Hisayama Study. Stroke 2003, 34(1 0):2349-2354.

18. A report by a committee established by the Director of the National Institute of Neurological Disorders and Stroke NloH, Bethesda, Maryland: Special report from the National Institute of Neurological Disorders and Stroke. Classification of cerebrovascular diseases III. Stroke 1990, 2 I(4):637-676.

19. Adams HP Jr, Bendixen BH, Kappelle LJ, Biller J, Love BB, Gordon DL, Marsh EE: Classification of subtype of acute ischemic stroke. Definitions for use in a multicenter clinical trial. TOAST. Trial of Org 10172 in Acute Stroke Treatment. Stroke 1993, 24(I):35-4I.

20. Cardiogenic brain embolism. Cerebral Embolism Task Force. Arch Neurol 1986, 43(I):71-84.

21. Tanizaki Y, Kiyohara Y, Kato I, Iwamoto H, Nakayama K, Shinohara $\mathrm{N}$, Arima $\mathrm{H}$, Tanaka $\mathrm{K}$, Ibayashi S, Fujishima M: Incidence and risk factors for subtypes of cerebral infarction in a general population: the Hisayama study. Stroke 2000, 3 I(I I):26| 6-2622.
22. Osawa H, Onuma H, Ochi M, Murakami A, Yamauchi J, Takasuka T, Tanabe F, Shimizu I, Kato K, Nishida W, et al.: Resistin SNP-420 determines its monocyte mRNA and serum levels inducing type 2 diabetes. Biochem Biophys Res Commun 2005, 335(2):596-602.

23. Osawa H, Tabara Y, Kawamoto R, Ohashi J, Ochi M, Onuma H, Nishida W, Yamada K, Nakura J, Kohara K, et al.: Plasma resistin, associated with single nucleotide polymorphism -420 , is correlated with insulin resistance, lower HDL cholesterol, and high-sensitivity C-reactive protein in the Japanese general population. Diabetes Care 2007, 30(6):150I-1506.

24. Osawa $\mathrm{H}$, Yamada $\mathrm{K}$, Onuma $\mathrm{H}$, Murakami A, Ochi M, Kawata $\mathrm{H}$, Nishimiya T, Niiya T, Shimizu I, Nishida W, et al:: The G/G genotype of a resistin single-nucleotide polymorphism at -420 increases type 2 diabetes mellitus susceptibility by inducing promoter activity through specific binding of Sp I/3. Am J Hum Genet 2004, 75(4):678-686.

25. Fisher CM: Lacunar strokes and infarcts: a review. Neurology 1982, 32(8):87|-876.

26. Tsukahara T, Nakashima E, Watarai A, Hamada $Y$, Naruse K, Kamiya H, Nakamura N, Kato N, Hamajima N, Sekido Y, et al.: Polymorphism in resistin promoter region at $\mathbf{- 4 2 0}$ determines the serum resistin levels and may be a risk marker of stroke in Japanese type 2 diabetic patients. Diabetes Res Clin Pract 2009, 84(2): $179-186$

27. Kolominsky-Rabas PL, Weber M, Gefeller O, Neundoerfer B, Heuschmann PU: Epidemiology of ischemic stroke subtypes according to TOAST criteria: incidence, recurrence, and long-term survival in ischemic stroke subtypes: a populationbased study. Stroke 200I, 32(I 2):2735-2740.

28. Saposnik G, Caplan LR, Gonzalez LA, Baird A, Dashe J, Luraschi A, Llinas R, Lepera S, Linfante I, Chaves C, et al.: Differences in stroke subtypes among natives and caucasians in Boston and Buenos Aires. Stroke 2000, 31(10):2385-2389.

29. Bokarewa M, Nagaev I, Dahlberg L, Smith U, Tarkowski A: Resistin, an adipokine with potent proinflammatory properties. Immunol 2005, 174(9):5789-5795.

30. Aquilante CL, Kosmiski LA, Knutsen SD, Zineh I: Relationship between plasma resistin concentrations, inflammatory chemokines, and components of the metabolic syndrome in adults. Metabolism 2008, 57(4):494-50I.

31. Kunnari A, Ukkola O, Kesaniemi YA: Resistin polymorphisms are associated with cerebrovascular disease in Finnish Type 2 diabetic patients. Diabet Med 2005, 22(5):583-589.

Publish with Bio Med Central and every scientist can read your work free of charge

"BioMed Central will be the most significant development for disseminating the results of biomedical research in our lifetime. "

Sir Paul Nurse, Cancer Research UK

Your research papers will be:

- available free of charge to the entire biomedical community

- peer reviewed and published immediately upon acceptance

- cited in PubMed and archived on PubMed Central

- yours - you keep the copyright 